\title{
In Vitro and in Planta Evaluation of Trichoderma asperellum TA as a Biocontrol Agent Against Phellinus noxius, the Cause of Brown Root Rot Disease of Trees
}

\author{
Hao Chou, ${ }^{1}$ Yi-Ting Xiao, ${ }^{2}$ Jyh-Nong Tsai, ${ }^{3}$ Ting-Ting Li, ${ }^{1}$ Hung-Yi Wu, ${ }^{2}$ Li-yu D. Liu, ${ }^{4}$ Der-Syh Tzeng, ${ }^{5}$ and Chia-Lin Chung ${ }^{1,2, \dagger}$ \\ ${ }^{1}$ Master Program for Plant Medicine, National Taiwan University, Taipei City 10617, Taiwan \\ ${ }^{2}$ Department of Plant Pathology and Microbiology, National Taiwan University, Taipei City 10617, Taiwan \\ ${ }^{3}$ Plant Pathology Division, Taiwan Agricultural Research Institute, Taichung City 41362, Taiwan \\ ${ }^{4}$ Department of Agronomy, National Taiwan University, Taipei City 10617, Taiwan \\ ${ }^{5}$ Department of Plant Pathology, National Chung Hsing University, Taichung City 40227, Taiwan
}

\begin{abstract}
Brown root rot (BRR), caused by the white rot fungus Phellinus noxius, is an epidemic disease of diverse broadleaved and coniferous tree species in many tropical and subtropical regions. Flooding and trenching control measures are difficult to implement, and chemical controls can have an adverse impact on ecosystems. Previous studies have provided in vitro evidence for the potential use of Trichoderma spp. for biocontrol of BRR. Here, we analyzed the in vitro antagonistic and mycoparasitic abilities of four Trichoderma spp. isolates against four P. noxius isolates in dual culture and Ficus microcarpa wood blocks. A convenient inoculation system based on root inoculation of a highly susceptible loquat (Eriobotrya japonica) with $P$. noxius-colonized wheat-oat grains was

and delaying the wilting of $P$. noxius-inoculated loquat cuttings in greenhouse trials. To understand the specific niche in which $T$. asperellum TA interacts with $P$. noxius, $\mathrm{KOH}$-aniline blue fluorescence microscopy was used to investigate the colonization of loquat roots by $P$. noxius and/or T. asperellum TA. Dilution plating assays were also conducted to quantify Trichoderma populations in the rhizosphere and potting mix. T. asperellum TA was able to robustly establish in the rhizosphere and potting mix but with scarce root penetration limited to the superficial layer. We discuss the timing and strategy for applying antagonistic Trichodema sp. on living trees or in BRR-infested areas for BRR management.
\end{abstract} developed to examine the effect of Trichoderma treatment in planta. Preventive application of Trichoderma asperellum TA, the isolate showing high antagonistic activity in vitro, was effective in preventing
Keywords: brown root rot (BRR), Phellinus noxius, Trichoderma, loquat, inoculation, root colonization, rhizosphere, microscopy
Brown root rot (BRR), caused by the white rot fungus Phellinus noxius (Corner) G. Cunningham, is a destructive epidemic disease of trees in tropical and subtropical areas in Southeast and East Asia, Oceania, Africa, Central America, and the Caribbean. During the last 20 years, BRR has become the most devastating tree disease in Taiwan (Chung et al. 2015), the Ryukyu Islands and the Ogasawara Islands of Japan (Akiba et al. 2015), Hong Kong, and Macao (Huang et al. 2016; Wu et al. 2011). P. noxius grows at temperatures ranging from 10 and 12 to $36^{\circ} \mathrm{C}$, with optimal growth at $30^{\circ} \mathrm{C}$. More than 200 plant species (in 59 families) are hosts of $P$. noxius; these mostly include broad-leaved and coniferous woody species but also, some herbaceous species (Ann et al. 2002). The pathogen has a $\sim 31-\mathrm{Mb}$ genome containing the highly expanded 1,3-beta-glucan synthase gene family and a comprehensive repertoire of genes encoding carbohydrate-active enzymes, which may

${ }^{\dagger}$ Corresponding author: C.-L. Chung; clchung@ntu.edu.tw

H. Chou and Y.-T. Xiao contributed equally to this work.

Funding: The work was funded by the Office of General Affairs, National Taiwan University; Taiwan Agricultural Research Institute; and Bureau of Animal and Plant Inspection and Quarantine, Council of Agriculture, Taiwan.

*The $\boldsymbol{e}$-Xtra logo stands for "electronic extra" and indicates that one supplementary figure and four supplementary tables are published online.

The author(s) declare no conflict of interest.

Accepted for publication 14 June 2019.

(C) 2019 The American Phytopathological Society account for its fast-growing nature and ability to infect a wide range of hosts (Chung et al. 2017). Population genomics analyses suggested that $P$. noxius is a hypervariable species, likely because of its bipolar heterothallic reproductive system and the prevalence of both monokaryotic and heterokaryotic states of mycelia in nature (Chung et al. 2017).

Infection by $P$. noxius usually begins in roots and gradually extends to the basal stem. The outer bark surface is covered with a dark brown mycelial mat of $P$. noxius and adhering soil particles, and the interior root tissue is decomposed, turning white and soft, with a widespread network of dark brown lines (Ann et al. 2002). Resupinate to sessile basidiocarps are formed on heavily infected trunks or stumps. Diseased trees show chlorotic, thin, and small leaves, and eventually, they decline within a few months to several years (Ann et al. 2002). Because of their decayed roots, infected trees easily fall down during strong winds and heavy rains, causing a threat to public safety. However, early detection of BRR is difficult, because trees infected with $P$. noxius often do not show obvious aboveground symptoms until the root system is extensively damaged. Evidence from whole-genome sequencing and simple sequence repeat markers suggested that $P$. noxius may disseminate over short distances via root-to-root contact between hosts and that genetically variable basidiospores are likely responsible for long-distance dispersal (Akiba et al. 2015; Chung et al. 2015, 2017).

Several physical and chemical control measures have been used to manage BRR. Because $P$. noxius can survive in a diseased tree stump for several years (Chang 1996), thorough removal of infected stump and wood residuals is critical and highly recommended. Trenching is a way to create a barrier to the spread of BRR through the interconnected root system. Approximately 1-m-deep trenches can be dug between diseased and healthy trees, 
covered with heavy-duty plastic sheets, and backfilled with soil (Forestry Bureau COA 2013). When applicable, flooding the infected area for 1 to 3 months can effectively eliminate $P$. noxius (Forestry Bureau COA 2013). A pot assay showed that, after 1 month of flooding, no viable $P$. noxius could be recovered from artificially infested wood (3 to $5 \mathrm{~cm}$ in diameter and 10-cm long) (Chang 1996). The biocidal fumigant dazomet $\left(60 \mathrm{~g} / \mathrm{m}^{3}\right.$ soil) or urea and lime (2 to $3 \mathrm{~kg}$ of urea and 0.2 to $0.3 \mathrm{~kg}$ of lime per $1 \mathrm{~m}^{3}$ of soil) can be used for field sanitation (Forestry Bureau COA 2013). Fungicides, such as Bordeaux mixture, propiconazole, triadimefon, prochloraz, and (benzothiazol-2-ylthio)methyl thiocyanate, used in concentrations as low as $10 \mathrm{ppm}$, were effective in inhibiting 95\% of the mycelial growth of $P$. noxius on potato dextrose agar (PDA) (Tsai et al. 2005). Drench treatment with these fungicides $(200 \mathrm{ml}$ of a $1,000-$ fold dilution per seedling once every month for 12 months) significantly reduced the incidence of wilting of sugar apple seedlings (Tsai et al. 2005).

Owing to concerns about environmental pollution and harmful effects to nontarget organisms, the demand for ecofriendly alternatives to chemical control has increased. Trichoderma spp. are efficient mycoparasites and ubiquitous components of mycoflora in soil and root ecosystems (Guzmán-Guzmán et al. 2019; Mukherjee et al. 2013). In agriculture, Trichoderma spp. have been widely used as biocontrol agents and biostimulants to inhibit pathogen infection, induce localized or systemic resistance, enhance abiotic stress tolerance, and improve plant growth and vigor (GuzmánGuzmán et al. 2019; Harman et al. 2004; Mukherjee et al. 2013). Some in vitro evidence suggested the use of Trichoderma spp. for BRR control. In dual cultures and interaction assays on wood blocks, diverse Trichoderma spp. (Trichoderma asperellum, Trichoderma atrovirde, Trichoderma fasciculatum, Trichoderma gamsii, Trichoderma ghanense, Trichoderma harzianum, Trichoderma koningiopsis, Trichoderma reesei, Trichoderma saturnisporum, Trichoderma spirale, and Trichoderma virens) showed antagonistic potential against $P$. noxius (Burcham et al. 2017b; Ribera et al. 2016; Schwarze et al. 2012) and many other wood decay fungi, such as Ganoderma austral (Schwarze et al. 2012), Ganoderma adspersum, Ganoderma lipsiense, Inonotus hispidus, Polyporus squamosus, Kretzschmaria deusta (Schubert et al. 2008), Antrodia serialis, Fibroporia vaillantii, Serpula himantioides, Gloeophyllum sepiarium, and Rhodonia placenta (Ribera et al. 2017). Field experiments showed that spraying or brushing a conidial suspension of Trichoderma spp. on pruning wounds helped reduce infection by naturally occurring and artificially inoculated wood decay fungi (Burcham et al. 2017a; Schubert et al. 2008). Applying T. harzianum on fresh-cut Norway spruce stumps reduced infection by Heterobasidion annosum (Nicolotti et al. 1999).

Compared with numerous studies of herbaceous and annual crops, the use of Trichoderma spp. on woody plants has been little studied. This study aimed to evaluate the use of Trichoderma spp. as a biocontrol agent for BRR. We investigated the antagonistic and mycoparasitic abilities of four Trichoderma spp. isolates against four $P$. noxius isolates in dual culture and ficus (Ficus microcarpa) wood blocks. A convenient $P$. noxius inoculation system based on cuttings of a highly susceptible loquat (Eriobotrya japonica) inoculated with $P$. noxius-colonized wheat-oat grains from roots was established to examine the preventive and curative effects of Trichoderma treatment in planta. Additionally, the specific niche in which $T$. asperellum TA interacts with $P$. noxius was explored through microscopy investigation of root infection and isolation of Trichoderma spp. from the rhizosphere and potting mix. The timing and strategy for applying Trichodema spp. for BRR management are discussed.

\section{Materials and Methods}

Selection and culture of $\boldsymbol{P}$. noxius and Trichoderma spp. Four $P$. noxius isolates $(2248,2252$, NTU5-7, and A42) and four Trichoderma spp. isolates (T. asperellum TA, T. virens GV22, T. asperellum ML01, and T. koningiopsis ML56) were used in this study
(Supplementary Table S1). P. noxius A42, collected from Yilan City in Taiwan, is a single-basidiospore isolate with a whole genome sequence available (Chung et al. 2015, 2017). P. noxius 2248, 2252, and NTU5-7 were isolated from $P$. noxius mycelial mats on infected trees located at different disease foci on the campus of National Taiwan University (Chung et al. 2015). In these foci, multiple ficus trees were sequentially infected and showed typical BRR symptoms within a few years, which suggests the relatively high virulence of the $P$. noxius isolates. The four Trichoderma spp. isolates used in this study showed better antagonistic activities against $P$. noxius A42 in preliminary dual-culture assays of eight Trichoderma spp. isolates (data not shown). The identity of each Trichoderma spp. was determined by alignment of the internal transcribed spacer and partial translation elongation factor 1-alpha sequences with those in the TrichOKEY 2 and TrichoBLAST databases (http://www.isth.info) (Druzhinina et al. 2005; Kopchinskiy et al. 2005).

$P$. noxius isolates were preserved as mycelium-agar discs in sterile water and stored at room temperature (Richter et al. 2010). Trichoderma spp. isolates were preserved as spore suspensions in $25 \%$ glycerol and stored at $-80^{\circ} \mathrm{C}$. Before conducting experiments, each $P$. noxius and Trichoderma sp. isolate was revived by culturing the stock on PDA at $30^{\circ} \mathrm{C}$ in the dark for 7 and 3 days, respectively. Agar discs were cut with a sterilized cork borer $(6 \mathrm{~mm}$ in diameter) from advancing margins of colonies of $P$. noxius and Trichoderma spp. and transferred to new plates for experiments.

Dual-culture antagonism assay. To observe the mycoparasitism of Trichoderma spp. against $P$. noxius, three mycelial discs $(1.5 \mathrm{~cm}$ apart) of each $P$. noxius and Trichoderma sp. isolate were placed at opposite sides of water agar plates $6.5 \mathrm{~cm}$ apart with the Trichoderma sp. inoculated 2 days after inoculation of $P$. noxius. After incubation in the dark at $30^{\circ} \mathrm{C}$ for 2 days, the number of Trichoderma hyphal coils encircling the hyphae of $P$. noxius was counted across the central line of the dual-culture plate under a light microscope. The formation of hyphal coils from the interaction between each $P$. noxius and Trichoderma sp. isolate was examined for three plates. Twoway analysis of variance (ANOVA) was performed to determine the effect of $P$. noxius isolate $(\mathrm{P})$, Trichoderma sp. isolate $(\mathrm{T})$, and their interactions $(\mathrm{P} \times \mathrm{T})$ on the formation of hyphal coils. Differences between all Trichoderma sp. $-P$. noxius combinations were determined by Tukey's honestly significant difference (HSD) test at $P<$ 0.05 using SAS Enterprise Guide 6.1 (SAS Institute Inc.).

The antagonistic activities of each Trichoderma sp. isolate against each $P$. noxius isolate were assessed on artificial media as described by Schubert et al. (2008) with modification. Mycelial discs of $P$. noxius and Trichoderma sp. isolates were placed on 1/2 PDA $5 \mathrm{~cm}$ apart with Trichoderma sp. inoculated 2 days after inoculation of $P$. noxius. After incubation in the dark at $30^{\circ} \mathrm{C}$ for 30 days, six agar discs (three proximal and three distal to the initial inoculation site of Trichoderma sp.) were cut with a sterilized cork borer $(6 \mathrm{~mm}$ in diameter) from the colony of P. noxius (Fig. 1A) and then transferred to $2 \%$ malt extract agar (MEA; $13.6 \mathrm{~g}$ of malt extract and $6.8 \mathrm{~g}$ of agar per 1 liter) amended with $230 \mathrm{mg} / \mathrm{liter}$ of thiabendazole (41.8\% suspension concentrate; Worldwide Agrochemical), which completely inhibited the growth of Trichoderma spp. The diameters of recovered $P$. noxius colonies were measured after 7 days of incubation at $30^{\circ} \mathrm{C}$ in dark. The experiment was conducted following a completely randomized design in two independent trials, with four plates per treatment per trial. Data from proximal and distal discs were analyzed separately. Two-way ANOVA was performed to determine the blocking effect (trial) and the effect of $P$. noxius isolate $(\mathrm{P})$, Trichoderma sp. isolate $(\mathrm{T})$, and their interactions $(\mathrm{P} \times \mathrm{T})$ on the colony sizes of surviving $P$. noxius. Differences between all Trichoderma sp. $-P$. noxius combinations were determined by Tukey's HSD test at $P<0.05$ using SAS Enterprise Guide 6.1 (SAS Institute Inc.).

Interaction test on wood blocks. An in vitro ficus wood block assay was conducted for all $P$. noxius-Trichoderma sp. combinations following the method described by Schubert et al. (2008) with modification. Wood blocks $(\sim 25 \times 25 \times 7 \mathrm{~mm})$ of $F$. microcarpa were oven dried at $105^{\circ} \mathrm{C}$ for $48 \mathrm{~h}$ to determine the initial dry weight 
and then, autoclaved at $121^{\circ} \mathrm{C}$ and $0.11 \mathrm{MPa}$ for $20 \mathrm{~min}$ before use. Sterilized wood blocks were subjected to four treatments. (1) P: wood blocks were placed onto 2 -week-old cultures of $P$. noxius on $2 \%$ MEA, incubated in the dark at $30^{\circ} \mathrm{C}$ for 1 week, and then, transferred to a new $2 \%$ MEA plate. (2) P-T: wood blocks were placed onto 2- week-old cultures of $P$. noxius on $2 \% \mathrm{MEA}$, incubated in the dark at $30^{\circ} \mathrm{C}$ for 1 week, and then, transferred to 1 -week-old cultures of a Trichoderma sp. on 2\% MEA. (3) T-P: wood blocks were placed onto 1-week-old cultures of a Trichoderma sp. on 2\% MEA, incubated in the dark at $30^{\circ} \mathrm{C}$ for 1 week, and then, transferred to
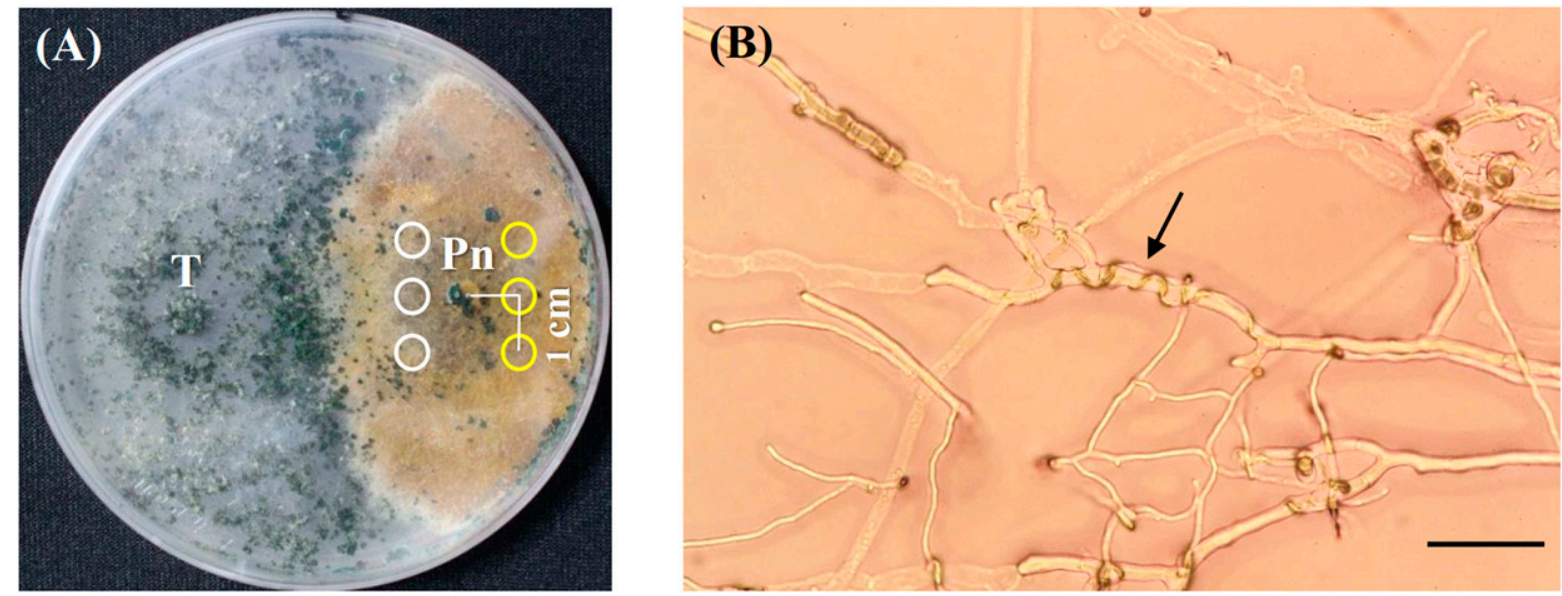

(C) P. noxius recovered from proximal discs

Trial 1

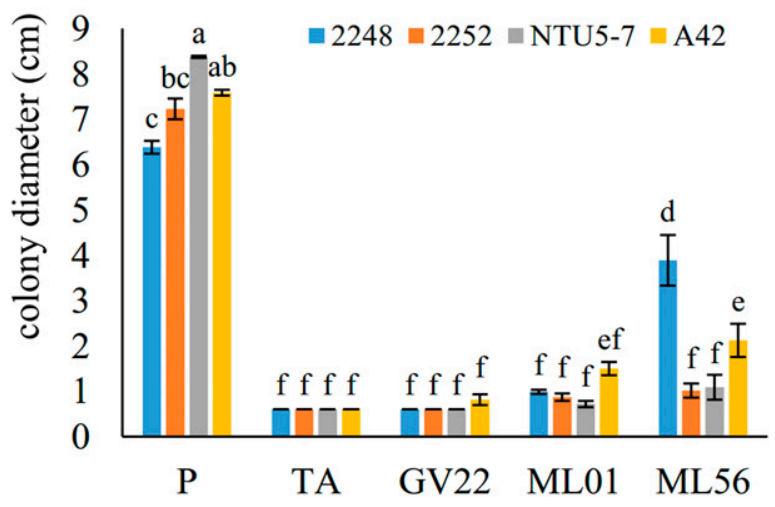

Trial 2

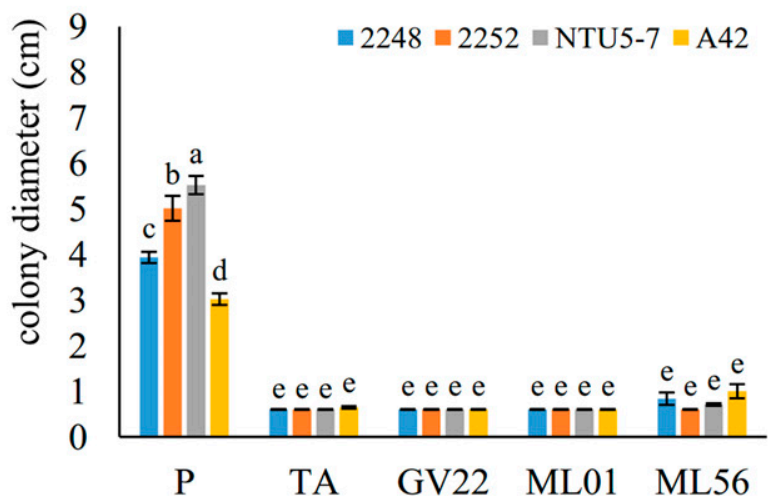

(D) P. noxius recovered from distal dises
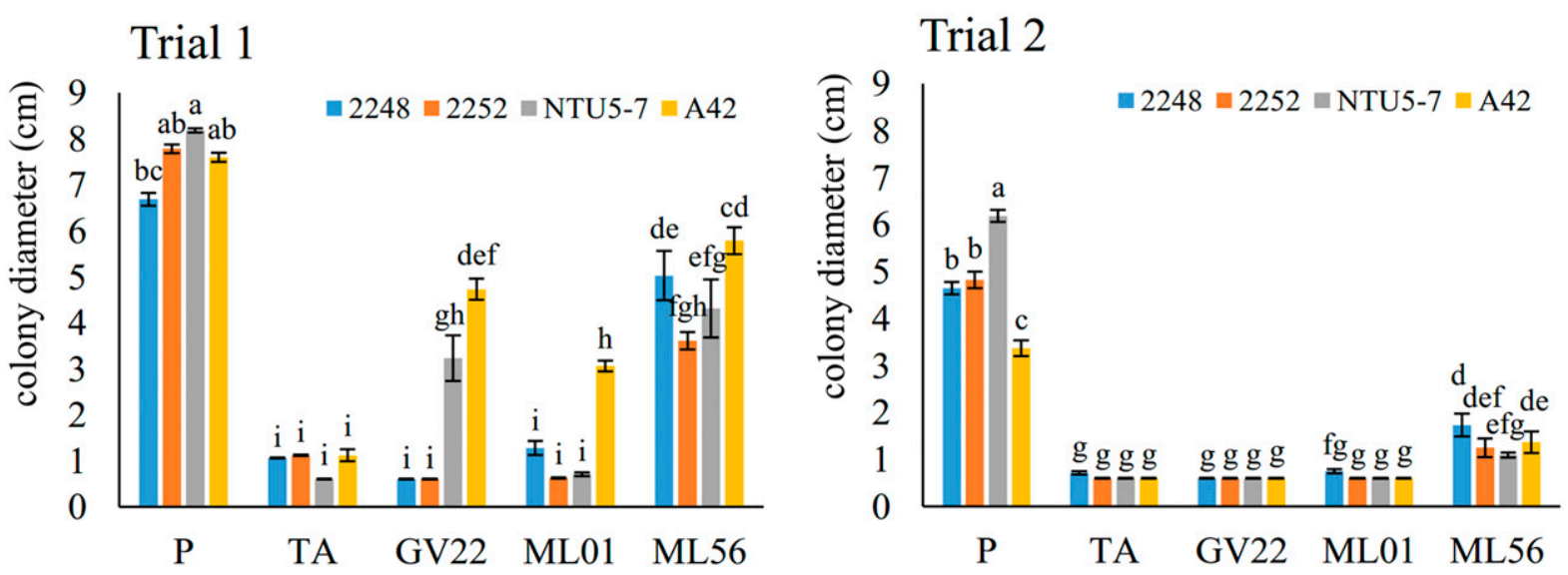

Fig. 1. Antagonistic inhibition of Phellinus noxius by Trichoderma spp. on artificial media. A, Colonies of Trichoderma asperellum TA and $P$. noxius 2248 after 30 days of dual culture on $1 / 2$ potato dextrose agar. Agar discs proximal and distal to the initial inoculation site of $T$. asperellum TA were transferred to new malt extract agar plates. White circles indicate proximal discs. Yellow circles indicate distal discs. The discs were $1 \mathrm{~cm}$ apart from each other and from inoculation site of $P$. noxius (Pn). T, inoculation site of $T$. asperellum TA. B, Mycoparasitic coils (arrow) of $T$. asperellum TA grew around the hyphae of $P$. noxius 2248 . Scale bar $=25 \mu \mathrm{m}$. C and $\mathrm{D}$, Colony sizes of surviving $P$. noxius isolates 2248,2252 , NTU5-7, and A42 growing out from the proximal and distal discs (6 mm in diameter) after 30 days of dual culture with T. asperellum TA, Trichoderma virens GV22, T. asperellum ML01, or Trichoderma koningiopsis ML56. Data (mean \pm standard error) with different letters are significantly different as determined by Tukey's honestly significant difference test at $P<0.05$. $P$, control (no Trichoderma sp.). 
2-week-old cultures of $P$. noxius. (4) T: wood blocks were placed onto 1-week-old cultures of a Trichoderma sp. on 2\% MEA, incubated in the dark at $30^{\circ} \mathrm{C}$ for 1 week, and then, transferred to a new $2 \%$ MEA plate. Subsequently, wood blocks from all treatments were incubated in the dark at $30^{\circ} \mathrm{C}$ for 12 weeks, surface cleaned to remove the mycelia, and oven dried at $105^{\circ} \mathrm{C}$ for $48 \mathrm{~h}$ to determine the dry weight loss. The experiment was conducted following a completely randomized design in two independent trials, with four wood blocks per treatment per trial. Two-way ANOVA was performed to determine the blocking effect (trial) and the effect of $P$. noxius isolate $(\mathrm{P})$, Trichoderma sp. isolate $(\mathrm{T})$, and their interactions $(\mathrm{P} \times \mathrm{T})$ on dry weight loss. The $\mathrm{P} \times \mathrm{T}$ effect consists of the "sequence" effect (preventive $[\mathrm{T}-\mathrm{P}]$ or curative treatment $[\mathrm{P}-\mathrm{T}]$ with Trichoderma $\mathrm{sp}$.) and the "residual" effect (the variation that cannot be explained by the "sequence" effect). For each $P$. noxius isolate versus four Trichoderma spp. isolates, differences between treatments were determined by Tukey's HSD test at $P<0.05$ using SAS Enterprise Guide 6.1 (SAS Institute Inc.). Differences between P, P-T, T-P, and T for the full dataset were also determined by Tukey's HSD test at $P<0.05$.

In planta assay. Antagonistic activity of $T$. asperellum TA toward $P$. noxius 2248 was evaluated using $\sim 2.5$-year-old rooted cuttings ( 70 to $100 \mathrm{~cm}$ in height; stem: 1 to $2 \mathrm{~cm}$ in diameter) of the $E$. japonica loquat cultivar Maomu. T. asperellum TA was selected because of its relatively better mycoparasitic and inhibitory activities against all four $P$. noxius isolates in dual-culture antagonism assays. The inoculum of $P$. noxius 2248 was prepared by culturing $P$. noxius on wheat-oat (1:1) grains (Ann et al. 1999a, b). In each 1-liter plastic jug, $50 \mathrm{~g}$ of wheat and $50 \mathrm{~g}$ of oat were placed in $50 \mathrm{ml}$ of distilled water $\left(\mathrm{dH}_{2} \mathrm{O}\right)$ containing $100 \mathrm{ppm}$ of chloramphenicol. The wheatoat grains were autoclaved twice (with a 2-day interval) at $121^{\circ} \mathrm{C}$ and $0.11 \mathrm{MPa}$ for $20 \mathrm{~min}$. About 1/2 plate of 5- to 7-day-old culture of $P$. noxius on PDA was cut into small pieces and transferred into the jug. The inoculated jugs were incubated in the dark at $30^{\circ} \mathrm{C}$ for 3 to 6 weeks, with jugs shaken every 2 days to prevent caking and accelerate fungal colonization. T. asperellum TA was cultured on PDA in the dark at $30^{\circ} \mathrm{C}$ for 7 days. Spores were dislodged using a glass rod and sterilized $\mathrm{dH}_{2} \mathrm{O}$ and adjusted to $2 \times 10^{5}$ conidia per milliliter using a hemocytometer.

Loquat plants were grown in topsoil in pots $(18$-cm diameter $\times 17$ $\mathrm{cm}$ height) in a greenhouse at Taiwan Agricultural Research Institute. For inoculation with $P$. noxius, soil attached to the roots was gently removed; then, the inoculum (60 $\mathrm{g}$ of $P$. noxius-colonized grains per plant) and soil were placed layer by layer over the roots until the whole root system was evenly covered (approximately three layers of $P$. noxius inoculum in between five layers of soil). For inoculation with $T$. asperellum TA, each plant was drench treated with $200 \mathrm{ml}$ of a spore suspension $\left(2 \times 10^{5}\right.$ conidia per milliliter). The in planta assay involved five treatments. (1) P: loquat inoculated with $P$. noxius 2248 alone. (2) P-T: loquat preinoculated with $P$. noxius 2248 , incubated for 2 weeks, and then, drenched with $T$. asperellum TA every week for 6 weeks starting from the second week. (3) T-P: loquat drenched with $T$. asperellum TA every week for 2 weeks, inoculated with $P$. noxius 2248 for 1 week, and then, drenched with $T$. asperellum TA every week for 5 weeks. (4) T: loquat drenched with T. asperellum TA every week for 8 weeks. (5) Control: no treatment. The plants were examined every week and photographed at 6 and 8 weeks postinoculation (wpi). The experiment was conducted following a completely randomized design in two independent trials, with six plants per treatment per trial. The results from two independent trials were combined to determine the incidence of wilting.

To examine the underground symptoms, the roots of each plant from independent trials 1 and 2 were gently washed and then photographed at 12 and 17 wpi, respectively. Samples from the 17th week were used for reisolation. For each plant, one to two main roots $(\sim 1-\mathrm{cm}$ diameter $)$ and five to six fine roots $(\sim 0.1-\mathrm{cm}$ diameter $)$ were randomly sampled. The roots were immersed in $75 \% \mathrm{EtOH}$ for $40 \mathrm{~s}$, $0.5 \%$ sodium hypochlorite for $40 \mathrm{~s}$, and then, sterile $\mathrm{dH}_{2} \mathrm{O}$ for 15 $\mathrm{s}$. The surface-sterilized roots were cut into $\sim 1-\mathrm{cm}$ segments and then, transferred to a modified $P$. noxius-selective medium, $\mathrm{MA}+4$ (20 g of malt extract, $20 \mathrm{~g}$ of agar, $10 \mathrm{mg}$ of benomyl, $10 \mathrm{mg}$ of dicloran, $100 \mathrm{mg}$ of chloramphenicol, and $500 \mathrm{mg}$ of gallic acid per 1 liter) (Chang 1995), and a modified Trichoderma-selective medium (TSM; $0.2 \mathrm{~g}$ of MgSO4.7H2O, $0.9 \mathrm{~g}$ of $\mathrm{K}_{2} \mathrm{HPO}_{4}, 0.1 \mathrm{~g}$ of $\mathrm{KCl}$, $1 \mathrm{~g}$ of $\mathrm{NH}_{4} \mathrm{NO}_{3}, 3 \mathrm{~g}$ of D-glucose, $0.15 \mathrm{~g}$ of rose bengal, $20 \mathrm{~g}$ of agar, $0.1 \mathrm{~g}$ of captan, $0.25 \mathrm{~g}$ of chloramphenicol, $0.08 \mathrm{~g}$ of metalaxyl, and $10 \mathrm{mg}$ of mepronil per 1 liter) (Askew and Laing 1993). After incubation in the dark at $30^{\circ} \mathrm{C}$ for 7 days, the isolation frequencies of $P$. noxius and the genus Trichoderma from the root segments were determined.

Microscopic analysis of root colonization. A modified $\mathrm{KOH}-$ aniline blue fluorescence microscopy method (Chung et al. 2010; Hood and Shew 1996) was used to visualize the hyphal growth of $P$. noxius 2248 and/or T. asperellum TA in loquat roots. Three fine roots were randomly sampled from each plant in two independent trials at 12 and 17 wpi. Segments $(\sim 3 \mathrm{~cm})$ cut from each root were pooled, incubated in $1 \mathrm{M} \mathrm{KOH}$ at room temperature for $72 \mathrm{~h}$, and then, autoclaved at $121^{\circ} \mathrm{C}$ and $0.11 \mathrm{MPa}$ for $21 \mathrm{~min}$. The autoclaved samples were rinsed with sterile double distilled water $\left(\mathrm{ddH}_{2} \mathrm{O}\right)$ three times and then, stored in sterile $\mathrm{ddH}_{2} \mathrm{O}$ for 3 to 5 days until examination. For each treatment, 10 to $16 \sim 0.5$-cm segments cut from 10 to 16 randomly chosen $\sim 3-\mathrm{cm}$ segments (one from each) were examined. The root segments were placed on microscopic slides and mounted in $0.05 \%$ aniline blue in $0.067 \mathrm{M} \mathrm{K}_{2} \mathrm{HPO}_{4}$ (prepared $2 \mathrm{~h}$ before use). The samples were examined under an Olympus BX51 microscope with a Wu filter (dichroic mirror DM400, excitation filter BP330-385, and barrier filter BA420).

Quantification of $T$. asperellum TA in the rhizosphere and potting mix. Five $\sim 2.5$-year-old loquat rooted cuttings were grown in potting mix (BVB substrates:perlite:vermiculite $=2: 1: 1$ ) in pots (18-cm diameter $\times 17-\mathrm{cm}$ height) in a greenhouse at the Department of Plant Pathology and Microbiology, National Taiwan University. The plants were drenched once with a spore suspension of $T$. asperellum TA $\left(2 \times 10^{5}\right.$ conidia per milliliter, $200 \mathrm{ml}$ per plant $)$. From each plant, three randomly chosen fine roots and three potting mix samples taken from a depth of $\sim 5 \mathrm{~cm}$ were harvested at 0 (before treatment), 1, 7, 14, 21, 28, and 35 days postinoculation (dpi). Samples of rhizosphere potting mix ( $~ 0.5 \mathrm{~cm}$ around roots) and potting mix ( $>3 \mathrm{~cm}$ away from roots) were air dried in a fume hood for 3 days before use. The dynamics of $T$. asperellum TA populations were assessed using the soil dilution plating method according to Hohmann et al. (2011). A 1-g rhizosphere potting mix or potting mix sample was vigorously mixed with $9 \mathrm{ml}$ of sterile $\mathrm{dH}_{2} \mathrm{O}$ and then, diluted to $10^{-1}, 10^{-2}$, and $10^{-3}$. Aliquots of each dilution were spread onto three plates of modified TSM (100 $\mu$ l per plate). After incubation in the dark at $30^{\circ} \mathrm{C}$ for 7 days, CFUs per $1 \mathrm{~g}$ rhizosphere potting mix or potting mix were calculated. One-way ANOVA was performed on the data. Differences between the quantities of $T$. asperellum TA in the rhizosphere and potting mix at $0,1,7,14,21,28$, and 35 dpi were analyzed by Tukey's HSD test at $P<0.05$ using SAS Enterprise Guide 6.1 (SAS Institute Inc.).

\section{Results}

Antagonistic inhibition of $P$. noxius by Trichoderma spp. on artificial media. In dual-culture tests on 1/2 PDA, all Trichoderma spp. isolates overgrew and colonized the cultures of all $P$. noxius isolates (Fig. 1A). Although there was no inhibition zone, the colony growth of $P$. noxius was clearly restricted. All four Trichoderma spp. isolates coiled around or grew along the hyphae of all $P$. noxius isolates (Fig. 1B). The degree of mycoparasitism was significantly associated with $P$. noxius isolate, Trichoderma sp. isolate, and their interactions (Supplementary Table S2). The mean numbers of mycoparasitic coils formed by different Trichoderma spp. isolates during interactions with the four $P$. noxius isolates ranged from 342 to 447 for TA, from 72 to 103 for GV22, from 231 to 427 for ML01, and from 233 to 365 for ML56 (Supplementary Fig. S1A). Overall, the ability to coil around $P$. noxius was greater for $T$. asperellum TA and ML01 than for T. virens GV22 (Supplementary Fig. S1B).

The lethal effects of the four Trichoderma spp. isolates toward the four $P$. noxius isolates were evaluated by transferring mycelium-agar discs to new plates after 30 days of dual culture. Colony sizes of 
surviving $P$. noxius isolates were significantly affected by $P$. noxius isolate, Trichoderma sp. isolate, and their interactions (Supplementary Table S3). The factor "trial" also had a significant effect, and therefore, the results from the two trials are shown separately (Fig. $1 C$ and D). The growth rate of $P$. noxius was lower in trial 2 than in trial 1 (the difference may be because of the use of $P$. noxius revived from the mycelium-agar discs preserved in different stock tubes). For most of the Trichoderma sp.-P. noxius combinations, the discs taken from the side proximal to Trichoderma spp. showed no or little growth of $P$. noxius (Fig. 1C). The discs taken from the distal side resulted in relatively lower mortality and larger colonies of $P$. noxius (Fig. 1D), thereby allowing better differentiation among the antagonistic activities of different Trichoderma spp. isolates. After interacting with Trichoderma spp. TA, GV22, ML01, and ML56, the sizes of $P$. noxius colonies from distal discs were reduced to 7.3 to $15.8,7.7$ to $62.3,8.1$ to 40.3 , and 46.4 to $76.2 \%$ of those of the control, respectively, in trial 1 and 9.7 to $17.8,9.7$ to $17.8,9.7$ to 17.8 , and 17.7 to $40.5 \%$ of those of the control, respectively, in trial 2 (Fig. 1D). These results suggested the following ranking of Trichoderma spp. based on the level of antagonistic inhibition of $P$. noxius on 1/2 PDA: TA $>$ ML01 $>$ GV22 > ML56 in trial 1 and TA $=$ ML01 $=$ GV22 $>$ ML56 in trial 2. Among the four Trichoderma spp. isolates, T. asperellum TA showed the most consistent inhibitory activity against all four $P$. noxius isolates in both trials.

In vitro evaluation of the antagonistic activity of Trichoderma spp. on wood blocks. The dry weight loss of wood blocks was significantly associated with $P$. noxius isolate, Trichoderma sp. isolate, and their interactions (Supplementary Table S4). The factors "trial" and "sequence" had no effect on dry weight loss. For all $P$. noxiusTrichoderma sp. combinations, the ranking of treatments based on mean dry weight loss was as follows: P $(9.3 \%)>\mathrm{P}-\mathrm{T}(3.1 \%) \geq$ T-P $(2.5 \%)>\mathrm{T}(1.5 \%)$ (Table 1). Treating ficus wood blocks with $P$. noxius alone $(\mathrm{P})$ resulted in significantly higher dry weight loss than treating with P-T, T-P, and T, which suggests that Trichoderma spp. isolates inhibited the wood decay induced by $P$. noxius. For each $P$. noxius isolate, no significant differences in the inhibitory effects of the four Trichoderma spp. isolate were observed (Table 1). The
$P$. noxius isolates 2248 showed a lower ability to decompose ficus wood than 2252, NTU5-7, and A42 (mean dry weight loss of 3.5\% versus 10.7 to $11.5 \%$ )

In planta evaluation of the antagonistic activity of $T$. asperellum TA. Consistent results were observed in two independent trials. Aboveground disease symptoms were not seen in control plants, plants treated with $T$. asperellum TA then $P$. noxius (T-P) or T. asperellum TA alone (T). The ranking of treatments based on overall incidence of wilting of loquat plants at 6 and 8 wpi was as follows: $\mathrm{P}(75 \%)>\mathrm{P}-\mathrm{T}(41.67 \%)>\mathrm{T}-\mathrm{P}=\mathrm{T}=$ control $(0 \%)$ (Fig. $2 \mathrm{~A}$ to E). The symptomatic plants in $\mathrm{P}$ and P-T started to decline at $\sim 2$ wpi: leaves turned droopy, reddish brown, and then, totally wilted within 7 to 14 days. In the P-T group, after weekly treatment with $T$. asperellum TA starting from the second week, no additional plants became wilted; however, plants that had already started to wilt did not recover.

We examined the effect of different treatments on loquat roots (Fig. 2A to E). Compared with the extensive root systems in the T-P, $\mathrm{T}$, and control treatments, the roots of wilted plants in the $\mathrm{P}$ and P-T treatments were severely and slightly decayed, respectively. After inoculation with $P$. noxius alone $(\mathrm{P})$, the surfaces of diseased roots showed a layer of mixture of soil particles and a mycelial mat of $P$. noxius; the interiors of the severely decayed roots were soft and white with brownish hyphal cords (Fig. 2F). No obvious difference in root appearance or volume was observed between the T-P, T, and control treatments.

To confirm whether the inoculations were successful and understand the frequencies of root colonization by $P$. noxius 2248 and/or T. asperellum TA, randomly sampled main and fine roots were used for reisolation of fungi on P. noxius- and TSM (Table 2). The ranking of treatments based on the isolation frequencies of P. noxius from main roots was $\mathrm{P}(86.7 \%)>\mathrm{P}-\mathrm{T}(6.7 \%)>\mathrm{T}-\mathrm{P}$ $(5.6 \%)>\mathrm{T}(0 \%)=$ control $(0 \%)$, and the ranking from fine roots was $\mathrm{P}(20.6 \%)>\mathrm{P}-\mathrm{T}(6.3 \%)>\mathrm{T}-\mathrm{P}(3.3 \%)>\mathrm{T}(0 \%)=$ control $(0 \%)$. However, the ranking of treatments based on the isolation frequencies of $T$. asperellum TA from main roots was $\mathrm{T}(11.1 \%)>\mathrm{P}-\mathrm{T}$ $(3.7 \%)>\mathrm{T}-\mathrm{P}(0 \%)=\mathrm{P}(0 \%)=$ control $(0 \%)$, and that from fine roots was $\mathrm{T}(4.2 \%)>\mathrm{P}-\mathrm{T}(0 \%)=\mathrm{T}-\mathrm{P}(0 \%)=\mathrm{P}(0 \%)=\operatorname{control}(0 \%)$.

Table 1. Inhibition effects of Trichoderma spp. isolates on Ficus microcarpa wood decomposition by Phellinus noxius

\begin{tabular}{|c|c|c|c|c|}
\hline \multirow{2}{*}{$\begin{array}{l}\text { P. noxius isolates and } \\
\text { Trichoderma } \text { spp. isolates } \mathrm{x}\end{array}$} & \multicolumn{4}{|c|}{ Dry weight loss (\%) of wood blocks treated with $P$. noxius and/or Trichoderma sp.y } \\
\hline & $\mathbf{P}^{\mathbf{z}}$ & P-T & T-P & $\mathbf{T}^{\mathbf{z}}$ \\
\hline \multicolumn{5}{|l|}{2248} \\
\hline TA & $3.5 \pm 0.97 \mathrm{a}$ & $2.9 \pm 0.22 \mathrm{abcd}$ & $2.7 \pm 0.12 \mathrm{abcd}$ & $1.5 \pm 0.18 \mathrm{bcd}$ \\
\hline GV22 & $3.5 \pm 0.97 \mathrm{a}$ & $3.4 \pm 0.34 \mathrm{abc}$ & $2.3 \pm 0.14 \mathrm{abcd}$ & $1.6 \pm 0.14 \mathrm{bcd}$ \\
\hline ML01 & $3.5 \pm 0.97 \mathrm{a}$ & $2.9 \pm 0.21 \mathrm{abcd}$ & $2.0 \pm 0.24 \mathrm{abcd}$ & $1.1 \pm 0.22 \mathrm{~d}$ \\
\hline ML56 & $3.5 \pm 0.97 \mathrm{a}$ & $3.5 \pm 0.36 \mathrm{abc}$ & $2.6 \pm 0.70 \mathrm{abcd}$ & $1.8 \pm 0.22 \mathrm{abcd}$ \\
\hline \multicolumn{5}{|l|}{2252} \\
\hline TA & $10.9 \pm 0.88 \mathrm{a}$ & $2.7 \pm 0.15 b c$ & $2.9 \pm 0.18 b c$ & $1.5 \pm 0.18 \mathrm{c}$ \\
\hline GV22 & $10.9 \pm 0.88 a$ & $3.5 \pm 0.24 \mathrm{~b}$ & $2.8 \pm 0.22 b c$ & $1.6 \pm 0.14 b c$ \\
\hline ML01 & $10.9 \pm 0.88 \mathrm{a}$ & $2.8 \pm 0.23 b c$ & $2.0 \pm 0.15 b c$ & $1.1 \pm 0.22 \mathrm{c}$ \\
\hline ML56 & $10.9 \pm 0.88 a$ & $3.4 \pm 0.20 \mathrm{~b}$ & $2.0 \pm 0.46 \mathrm{bc}$ & $1.8 \pm 0.22 b c$ \\
\hline \multicolumn{5}{|l|}{ NTU5-7 } \\
\hline TA & $11.5 \pm 1.73 \mathrm{a}$ & $2.6 \pm 0.11 \mathrm{~b}$ & $2.9 \pm 0.14 \mathrm{~b}$ & $1.5 \pm 0.18 \mathrm{~b}$ \\
\hline GV22 & $11.5 \pm 1.73 \mathrm{a}$ & $3.0 \pm 0.24 \mathrm{~b}$ & $2.9 \pm 0.23 b$ & $1.6 \pm 0.14 \mathrm{~b}$ \\
\hline ML01 & $11.5 \pm 1.73 \mathrm{a}$ & $2.9 \pm 0.21 \mathrm{~b}$ & $2.1 \pm 0.15 b$ & $1.1 \pm 0.22 \mathrm{~b}$ \\
\hline ML56 & $11.5 \pm 1.73 \mathrm{a}$ & $3.1 \pm 0.16 b$ & $1.9 \pm 0.30 \mathrm{~b}$ & $1.8 \pm 0.22 \mathrm{~b}$ \\
\hline \multicolumn{5}{|l|}{ A42 } \\
\hline $\mathrm{TA}$ & $10.7 \pm 1.35 \mathrm{a}$ & $3.0 \pm 0.19 b c$ & $3.0 \pm 0.21 b c$ & $1.5 \pm 0.18 b c$ \\
\hline GV22 & $10.7 \pm 1.35 \mathrm{a}$ & $2.9 \pm 0.25 b c$ & $2.7 \pm 0.22 b c$ & $1.6 \pm 0.14 b c$ \\
\hline ML01 & $10.7 \pm 1.35 \mathrm{a}$ & $2.6 \pm 0.20 b c$ & $2.6 \pm 0.19 b c$ & $1.1 \pm 0.22 \mathrm{c}$ \\
\hline ML56 & $10.7 \pm 1.35 \mathrm{a}$ & $4.3 \pm 0.47 \mathrm{~b}$ & $3.0 \pm 0.69 \mathrm{bc}$ & $1.8 \pm 0.22 b c$ \\
\hline Overall & $9.3 \pm 0.74 \mathrm{a}$ & $3.1 \pm 0.07 \mathrm{~b}$ & $2.5 \pm 0.10 b$ & $1.5 \pm 0.08 \mathrm{c}$ \\
\hline
\end{tabular}

x 2248: P. noxius 2248; 2252: P. noxius 2252; NTU5-7: P. noxius 2248; A42: P. noxius A42; GV22, Trichoderma virens GV22; ML01, Trichoderma asperellum ML01; ML56, Trichoderma koningiopsis ML56; TA, T. asperellum TA.

${ }^{y}$ Results from the assays of each $P$. noxius isolate versus four Trichoderma spp. isolates were analyzed together. Data (mean \pm standard error) with different letters are significantly different as determined by Tukey's honestly significant difference test at $P<0.05$. $\mathrm{P}, P$. noxius only; P-T, $P$. noxius-colonized wood block treated with Trichoderma sp.; T, Trichoderma sp. only; T-P, Trichoderma sp.-colonized wood block treated with $P$. noxius.

${ }^{\mathrm{z}}$ The same sets of $\mathrm{P}$ and $\mathrm{T}$ were used as the control for different P-T and T-P combinations, and therefore, some data in columns $\mathrm{P}$ and $\mathrm{T}$ are identical. 
Microscopy observation of root colonization of loquat roots by $\boldsymbol{P}$. noxius and/or T. asperellum TA. $\mathrm{KOH}$-aniline blue fluorescence microscopy was used for histological examination of fungal colonization in roots (Fig. 3). Despite the background fluorescence noise from the vascular system, it was easy to observe interior and surface root colonization by fungal hyphae under the microscope. No hyphae were detected with the control treatment (Fig. 3E). Inoculation with $P$. noxius alone $(\mathrm{P})$ caused abundant colonization and destructive degradation of all tested root segments (Fig. 3A). Melanized $P$. noxius hyphae and soil particles adhering to the roots were generally observed. With $T$. asperellum TA alone (T), only $23 \%$ of the root segments showed scarce hyphae (a few hyphal strands observed at one or two sites on each 0.5 -cm segment); the hyphae localized mostly on the outer surface, with occasional penetration of the root epidermis (Fig. 3D). For roots treated with P. noxius then $T$. asperellum TA (P-T), although abundant colonization of $P$. noxius was seen in all tested root segments, little decay and no melanized hyphae were observed (Fig. 3C). Treatment with $T$. asperellum TA then $P$. noxius (T-P) resulted in moderate colonization of $P$. noxius in fewer (40\%) root segments (Fig. 3B).

Trichoderma population dynamics in the rhizosphere and potting mix. In the root system of loquat plants grown in pots (Fig. 4), no T. asperellum TA was detected in the potting mix before inoculation of T. asperellum TA ( $0 \mathrm{dpi})$. At $7 \mathrm{dpi}$, the concentration
(A) $\mathbf{P}$

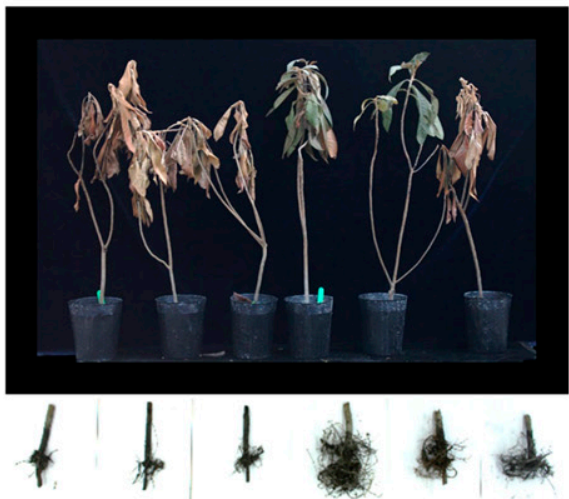

(D) $\mathrm{T}$
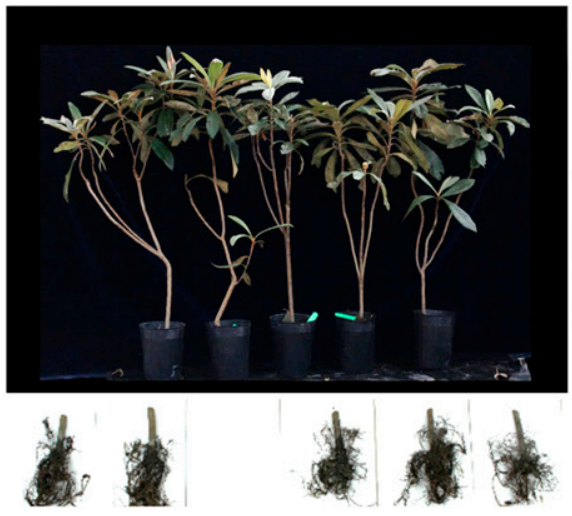

(B) P-T

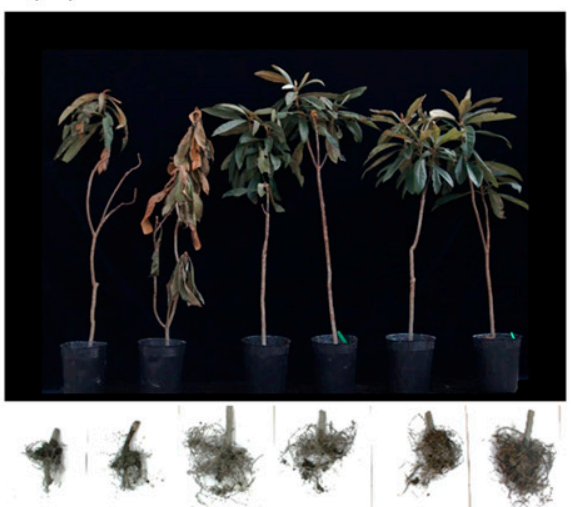

(E) Control

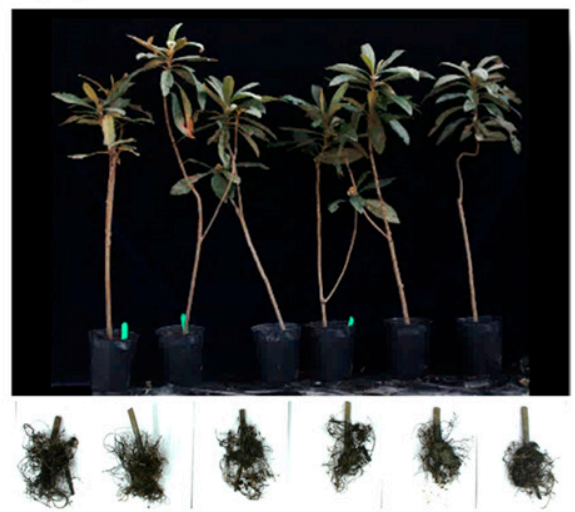

(C) T-P

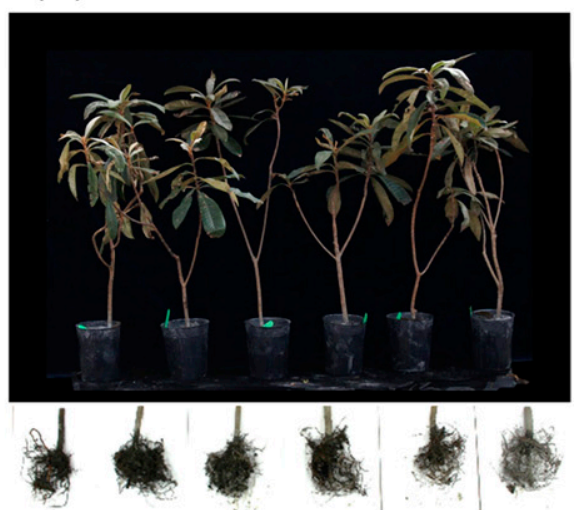

(F)

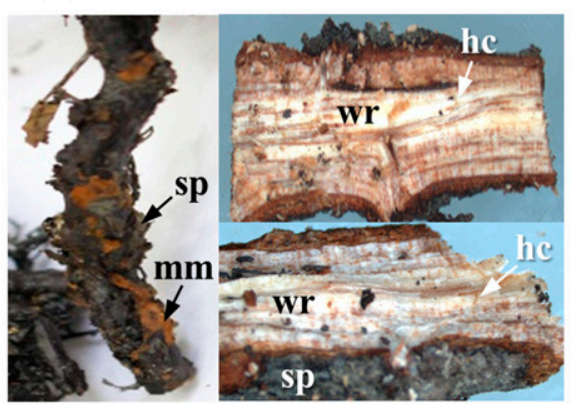

Fig. 2. Inhibition effect of Trichoderma asperellum TA on the infection of loquat (Eriobotrya japonica) cuttings by Phellinus noxius 2248 . A, $P$ indicates loquat inoculated with $P$. noxius 2248 alone. B, P-T indicates loquat preinoculated with $P$. noxius 2248, incubated for 2 weeks, and then, drenched with T. asperellum TA every week for 6 weeks. C, T-P indicates loquat drenched with $T$. asperellum TA for the first 2 weeks, inoculated with $P$. noxius 2248, and then, drenched with $T$. asperellum TA every week for 5 weeks. D, Loquat drenched with $T$. asperellum TA every week for 8 weeks. $\mathbf{E}$, Control indicates no treatment. F, Appearance and longitudinal sections of the main roots of loquat inoculated with $P$. noxius. Photos of aboveground and root symptoms were taken at 8 and 12 weeks postinoculation, respectively. hc, brownish hyphal cord; mm, mycelial mat; sp, soil particle; wr, white rot.

Table 2. Isolation frequencies of Phellinus noxius and Trichoderma asperellum TA from loquat (Eriobotrya japonica) roots

\begin{tabular}{|c|c|c|c|c|c|c|c|c|}
\hline \multirow[b]{3}{*}{ Treatment $^{\mathbf{y}}$} & \multicolumn{4}{|c|}{$P$. noxius on $\mathrm{MA}+4^{\mathrm{x}}$} & \multicolumn{4}{|c|}{ T. asperellum TA on modified TSM } \\
\hline & \multicolumn{2}{|c|}{ Fine root } & \multicolumn{2}{|c|}{ Main root } & \multicolumn{2}{|c|}{ Fine root } & \multicolumn{2}{|c|}{ Main root } \\
\hline & $\begin{array}{c}\text { Ratio of } \\
\text { fragments }\end{array}$ & $\begin{array}{c}\text { Isolation } \\
\text { frequency }(\%)\end{array}$ & $\begin{array}{c}\text { Ratio of } \\
\text { fragments }\end{array}$ & $\begin{array}{c}\text { Isolation } \\
\text { frequency }(\%)\end{array}$ & $\begin{array}{c}\text { Ratio of } \\
\text { fragments }\end{array}$ & $\begin{array}{c}\text { Isolation } \\
\text { frequency }(\%)\end{array}$ & $\begin{array}{c}\text { Ratio of } \\
\text { fragments }\end{array}$ & $\begin{array}{c}\text { Isolation } \\
\text { frequency }(\%)\end{array}$ \\
\hline Control & $0 / 210$ & 0 & $0 / 36$ & 0 & $0 / 175$ & 0 & $0 / 66$ & 0 \\
\hline $\mathrm{P}$ & $36 / 175$ & 20.6 & $26 / 30$ & 86.7 & $0 / 140$ & 0 & $0 / 60$ & 0 \\
\hline P-T & $11 / 175$ & 6.3 & $2 / 30$ & 6.7 & $0 / 147$ & 0 & $2 / 54$ & 3.7 \\
\hline $\mathrm{T}-\mathrm{P}$ & $7 / 210$ & 3.3 & $2 / 36$ & 5.6 & $0 / 175$ & 0 & $0 / 66$ & 0 \\
\hline $\mathrm{T}$ & $0 / 168$ & 0 & $0 / 72$ & 0 & $7 / 168$ & 4.2 & $8 / 72$ & 11.1 \\
\hline
\end{tabular}

${ }^{\mathrm{x}} \mathrm{MA}+4$ is a modified P. noxius-selective medium (20 g of malt extract, $20 \mathrm{~g}$ of agar, $10 \mathrm{mg}$ of benomyl, $10 \mathrm{mg}$ of dicloran, $100 \mathrm{mg}$ of chloramphenicol, and 500 mg of gallic acid per 1 liter).

y Control, no treatment; P, loquat inoculated with $P$. noxius 2248 alone; P-T, loquat preinoculated with $P$. noxius 2248 , incubated for 2 weeks, and then, drenched with T. asperellum TA every week for 6 weeks; T, loquat drenched with T. asperellum TA every week for 8 weeks; T-P, loquat drenched with T. asperellum TA for the first 2 weeks, inoculated with P. noxius 2248, and then, drenched with T. asperellum TA every week for 5 weeks; TSM, Trichoderma-selective medium.

${ }^{\mathrm{z}}$ Number of root fragments from which the targeted fungus was detected/total number of root fragments. 
of $T$. asperellum TA in the potting mix was significantly higher than that in the rhizosphere. At 21,28 , and $35 \mathrm{dpi}, T$. asperellum TA populations in the potting mix and rhizosphere were established at similar levels at about 3.1 to $6.3 \times 10^{4} \mathrm{CFU}$ per $1 \mathrm{~g}$ of dry potting mix.

\section{Discussion}

BRR has been a serious threat to a wide variety of perennial trees in agricultural, forest, and urban environments in many tropical and subtropical regions (Ann et al. 2002; Chung et al. 2017). In Taiwan, BRR accounted for $\sim 36 \%$ of the 1,038 cases reported to the Forest Disease Information Center in 2017 (2017 Annual Report of Taiwan Forestry Research Institute). Among the control measures available for BRR, flooding and trenching are usually difficult to implement or are not applicable for certain planting environments, and soil fumigation and drenching with chemicals can have adverse effects on ecosystems. Although effective and ecofriendly alternatives are in great demand, research has been constrained by the lack of an efficient in planta screening system. Trichoderma spp. have been shown to inhibit the growth of $P$. noxius on culture media and wood blocks (Burcham et al. 2017b; Ribera et al. 2016; Schwarze et al. 2012), but the antagonistic interactions or potential control effects have not been examined in planta.

This study started with in vitro analyses of the antagonistic and mycoparasitic abilities of four Trichoderma spp. isolates against four $P$. noxius isolates. A single isolate showing strong antagonistic activity, T. asperellum TA, was further found to be effective in delaying the wilting of $P$. noxius 2248-inoculated loquat cuttings in greenhouse trials. In planta assays suggested that better biocontrol efficiency could be obtained by applying $T$. asperellum TA before $P$. noxius infection is established. In addition to T. asperellum TA, $T$. virens GV22 and T. asperellum ML01 also showed good antagonistic activities against $P$. noxius in dual-culture and wood block assays, suggesting their potential as biocontrol agents for BRR. Additional investigations should be done to understand whether these antagonistic strains possess other desirable traits, such as environmental persistence and plant growth-promoting effects. Whether a single strain or multiple strains of Trichoderma spp. provides better control of BRR in the field also needs to be tested.

The pathogenicity and virulence of $P$. noxius on different hosts have been evaluated by artificially inoculating seedlings or rooted cuttings from wounded basal stems with $P$. noxius-colonized wheat-oat grains (Ann et al. 1999a, b), wounded tap roots with $P$. noxius-inoculated sawdust (Sahashi et al. 2010, 2014), and roots with pieces of $P$. noxius-colonized twigs (Chang 1995) or diseased soil and debris collected from an infected field (Tsai et al. 2005). In this study, we obtained a good infection rate by applying the easily prepared inoculum, $P$. noxius-colonized wheat-oat grains, evenly over the root system of loquat cuttings: $75 \%$ of plants wilted, and $P$. noxius was recovered from $86.7 \%$ of main root segments. Higher recovery rates of both $P$. noxius and $T$. asperellum TA were obtained from main roots than from fine roots, possibly because of different effects of the surface sterilization process on main and fine roots. Consistent

\section{(A) $\mathbf{P}$}

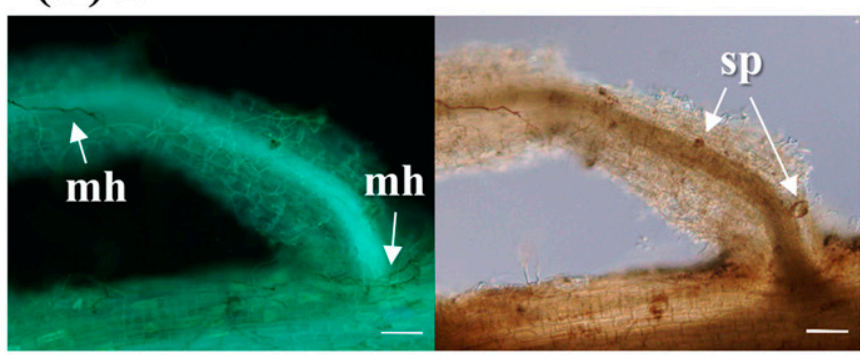

\section{(C) P-T}
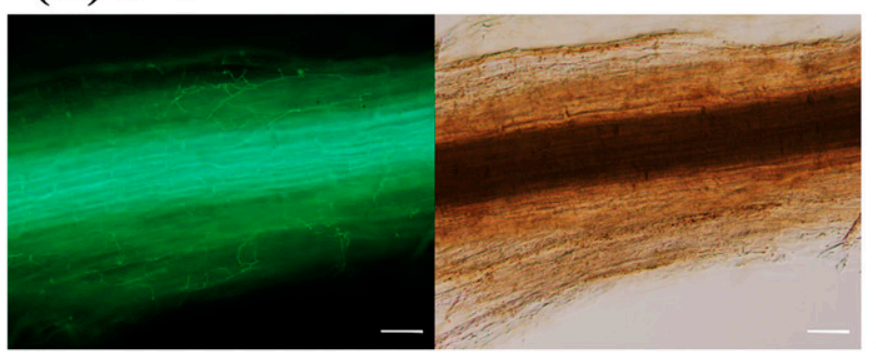

(D) $\mathrm{T}$

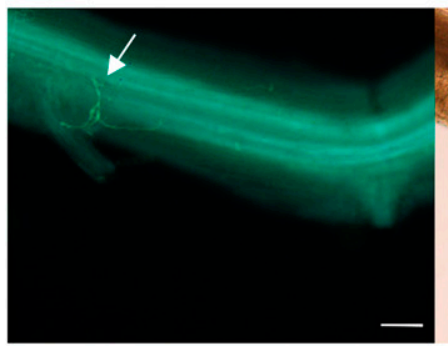

\section{(B) T-P}

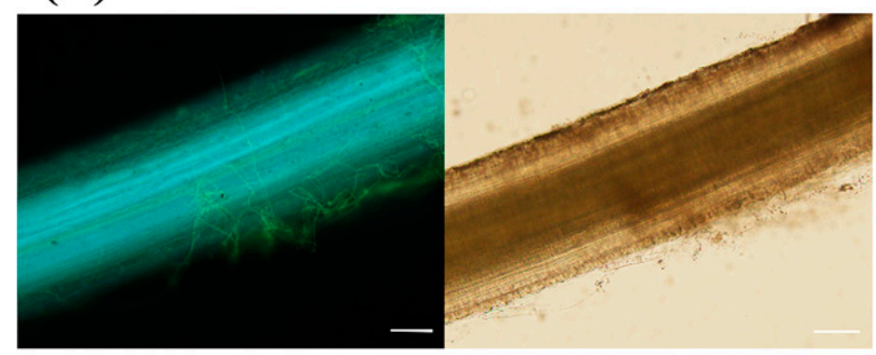

\section{P-T}

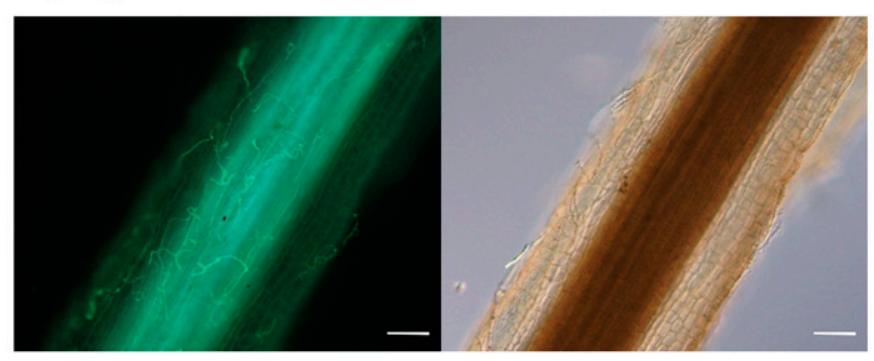

(E) Control

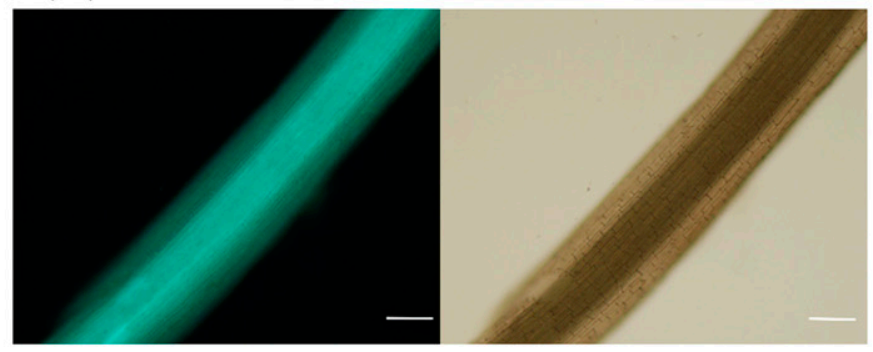

Fig. 3. Micrographs of the colonization of Phellinus noxius 2248 and Trichoderma asperellum TA in loquat roots. A, $P$ indicates loquat inoculated with $P$. noxius 2248 alone. mh, melanized hyphae; sp, soil particle. B, T-P indicates loquat drenched with $T$. asperellum TA for the first 2 weeks, inoculated with $P$. noxius 2248 , and then, drenched with $T$. asperellum TA every week for 5 weeks. C, P-T indicates loquat preinoculated with P. noxius 2248, incubated for 2 weeks, and then, drenched with $T$. asperellum TA every week for 6 weeks. D, Loquat drenched with T. asperellum TA every week for 8 weeks. Scarce hyphae (arrow) were found, mostly on the outer surface but with occasional penetration of the epidermis. E, Control indicates no treatment. Samples were collected 12 weeks postinoculation. Left and right photos were viewed in the fluorescent and light fields, respectively. Scale bars $=20 \mu \mathrm{m}$. 
with field observations (Ann et al. 1999a, 2002), the interiors of inoculated roots showed white rot with brownish hyphal cords, and a mycelial mat of $P$. noxius and soil particles was attached to the surface. Loquat was previously found to be one of the most highly susceptible hosts among 101 varieties (92 species) of horticultural woody plants tested (Ann et al. 1999b). In our repeated inoculation trials, typical quick decline symptoms could be observed within 2 to $5 \mathrm{wpi}$, making loquat an ideal indicator host for efficient screening of biocontrol agents for BRR. Compared with the wounded stem inoculation method (Ann et al. 1999b), direct root inoculation better reflects the natural infection process.

Our microscopy analysis and dilution plating assays revealed that, during interaction with loquat cuttings, $T$. asperellum TA could abundantly colonize the rhizosphere and potting mix, but root penetration was scarce and limited to the superficial layer. Many Trichoderma spp. can establish robustly in the rhizosphere and soil because of their high saprophytic and epiphytic activities (Mukherjee et al. 2013). T. harzianum could colonize the roots of cucumber and tomato seedlings mainly through intercellular hyphal growth in the epidermis and cortical area (Chacón et al. 2007; Yedidia et al. 1999). However, when T. harzianum was applied to 10-month-old olive plants, colonization of $T$. harzianum was profuse on the root surface but absent in the inner root (Ruano-Rosa et al. 2016). Because Trichoderma spp. does not readily colonize the roots of woody plants, the rhizosphere and rhizoplane are the expected niches for direct antagonism of Trichoderma spp. against root-attacking pathogens, such as $P$. noxius. This finding has important implications for biocontrol of BRR on living trees. For symptomatic trees, which usually have heavy colonization of $P$. noxius in the inner root tissues, Trichoderma spp. cannot effectively fight against the infection and eliminate the pathogen. However, asymptomatic trees adjacent to diseased trees/ stumps may be healthy or have a minor infection. Preventive application of antagonistic Trichoderma spp. on neighboring trees (which are at high risk) can protect the rhizosphere and probably, also prime plant defenses (Harman et al. 2004; Mukherjee et al. 2013; RuanoRosa et al. 2016), thus helping to stop the spread of BRR through root infection. In our in planta assay, loquat showed no aboveground symptoms when treated with $T$. asperellum TA then $P$. noxius (T$\mathrm{P}$ ), whereas treatment with $P$. noxius then $T$. asperellum TA (P-T) did not aid the recovery of symptomatic plants (although the infection and colonization of $P$. noxius in loquat roots were reduced). These results also suggest the preventive but not curative effect of T. asperellum TA on BRR.

Despite some variation, all four Trichoderma spp. isolates were effective in protecting ficus wood blocks against decomposition by

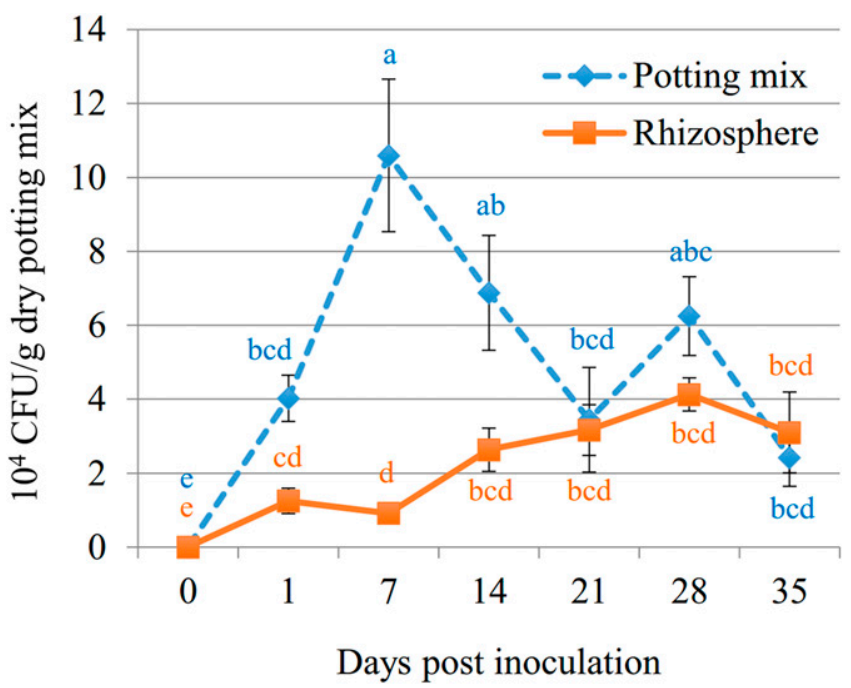

Fig. 4. Sizes of Trichoderma populations recovered from the potting mix and rhizosphere. Data (mean \pm standard error) with different letters are significantly different as determined by Tukey's honestly significant difference test at $P<0.05$. different $P$. noxius isolates. The results were consistent with the observations of Schwarze et al. (2012) and Burcham et al. (2017b), who tested different Trichoderma spp. versus $P$. noxius isolates on wood blocks of different tree species (including Delonix regia, Jacaranda mimosifolia, Ficus benjamina, Araucaria bidwillii, Khaya senegalensis, and Samanea saman). Dry weight losses caused by different $P$. noxius isolates can vary greatly. Schwarze et al. (2012) found that, for $F$. benjamina wood blocks treated with four $P$. noxius isolates, the dry weight losses after 3 months of incubation ranged from 9.8 to $23.3 \%$. The ability of Trichoderma spp. to antagonize $P$. noxius on wood suggests the potential of applying Trichoderma spp. in BRR-infested areas for bioremediation. The eradicative effect of T. harzianum T-TMS1 has been examined in vitro by incubating P. noxius- and T. harzianum T-TMS1-preinoculated balsa (Ochroma lagopus) wood together in containers with vermiculite at $70 \% \mathrm{RH}$; after 24 weeks of coincubation, no $P$. noxius could be recovered from the wood fragments extracted from the center parts of samples (Ribera et al. 2016). Of note, compared with $P$. noxius alone, which caused 3.5 to $11.5 \%$ weight loss, treatment with $T$. asperellum TA, $T$. virens GV22, T. asperellum ML01, or T. koningiopsis ML56 alone for 3 months resulted in as little as 1.1 to $1.8 \%$ weight loss. This finding indicates the relatively poor ability of these Trichoderma spp. isolates to decompose wood. Therefore, although bioremediation with Trichoderma spp. seems promising, removal of diseased stumps and as much wood debris in BRR-infested areas as possible before the application of Trichoderma sp. is needed to achieve an optimal eradicative outcome.

In conclusion, we recommend preventively applying antagonistic Trichoderma sp. on living trees at high risk (e.g., asymptomatic trees close to the diseased tree) or using Trichoderma sp. in BRR-infested areas (after thorough cleanup of infected stumps and residual wood) for bioremediation. The infested areas or root zones (typically 1.5 times the width of the tree canopy) can be treated by drenching soil with a suspension of Trichoderma sp. To obtain $10^{4}$ to $10^{6}$ conidia per $1 \mathrm{~cm}^{2}, 2$ liters of suspension $\left(5 \times 10^{4}\right.$ to $5 \times 10^{6}$ conidia per milliliter) per $1 \mathrm{~m}^{2}$ can be used for drench treatment. Frequent application (e.g., biweekly or monthly) of higher concentrations of the inoculum will result in better protective and eradicative results. For replantation in BRR-infested areas, roots of seedlings and cuttings can be dipped before transplanting, and then, soil drenching can be applied every 1 to 3 months to protect the transplanted plants (ElMohamedy 2009).

\section{Acknowledgments}

We thank Dr. Shean-Shong Tzean and Dr. Pao-Jen Ann for advising us on Phellinus noxius culturing, inoculation, and controls. We thank Schung-Ching Chiu, $\mathrm{Yu}-\mathrm{Ching}$ Huang, and Pei-Che Chung for providing P. noxius and Trichoderma spp. isolates. We thank Zong-Chi Wu and Yu-Wen Huang for help with molecular identification of Trichoderma spp. We appreciate help from Szu-Yu Chen for statistical analysis and Qiao-Juan Lai, Heng-An Lin, and Ya-Yun Chang for preliminary antagonistic activity tests. We also thank Pi-Ho Huang and Shun-Yuan Huang for help with greenhouse trials.

\section{Literature Cited}

Akiba, M., Ota, Y., Tsai, I. J., Hattori, T., Sahashi, N., and Kikuchi, T. 2015. Genetic differentiation and spatial structure of Phellinus noxius, the causal agent of brown root rot of woody plants in Japan. PLoS One 10: e0141792.

Ann, P.-J., Chang, T.-T., and Ko, W.-H. 2002. Phellinus noxius brown root rot of fruit and ornamental trees in Taiwan. Plant Dis. 86:820-826.

Ann, P.-J., Lee, H.-L., and Tsai, J.-N. 1999a. Survey of brown root disease of fruit and ornamental trees caused by Phellinus noxius in Taiwan. Plant Pathol. Bull. 8:51-60.

Ann, P.-J., Tsai, J.-N., Wang, I.-T., and Hsien, M.-L. 1999b. Response of fruit trees and ornamental plants to brown root rot disease by artificial inoculation with Phellinus noxius. Plant Pathol. Bull. 8:61-66.

Askew, D. J., and Laing, M. D. 1993. An adapted selective medium for the quantitative isolation of Trichoderma species. Plant Pathol. 42:686-690.

Burcham, D. C., Abarrientos, N. V., Jr., Wong, J. Y., Ali, M. I. M., Fong, Y. K., and Schwarze, F. W. 2017a. Field evaluation of Trichoderma spp. as a biological control agent to prevent wood decay on Benin mahogany (Khaya grandifoliola) and rain tree (Samanea saman) in Singapore. Biol. Control 114:114-124.

Burcham, D. C., Wong, J. Y., Abarrientos, N. V., Ali, M. I. M., Fong, Y. K., and Schwarze, F. W. 2017b. In vitro evaluation of antagonism by Trichoderma spp. 
towards Phellinus noxius associated with rain tree (Samanea saman) and Senegal mahogany (Khaya senegalensis). bioRxiv 151753.

Chacón, M. R., Rodríguez-Galán, O., Benítez, T., Sousa, S., Rey, M., Llobell, A., and Delgado-Jarana, J. 2007. Microscopic and transcriptome analyses of early colonization of tomato roots by Trichoderma harzianum. Int. Microbiol. 10:19-27.

Chang, T.-T. 1995. Decline of nine tree species associated with brown root rot caused by Phellinus noxius in Taiwan. Plant Dis. 79:962-965.

Chang, T.-T. 1996. Survival of Phellinus noxius in soil and in the roots of dead host plants. Phytopathology 86:272-276.

Chung, C.-L., Huang, S.-Y., Huang, Y.-C., Tzean, S.-S., Ann, P.-J., Tsai, J.-N., Yang, C.-C., Lee, H.-H., Huang, T.-W., and Huang, H.-Y. 2015. The genetic structure of Phellinus noxius and dissemination pattern of brown root rot disease in Taiwan. PLoS One 10:e0139445.

Chung, C. L., Lee, T. J., Akiba, M., Lee, H. H., Kuo, T. H., Liu, D., Ke, H. M., Yokoi, T., Roa, M. B., and Lu, M. Y. J. 2017. Comparative and population genomic landscape of Phellinus noxius: A hypervariable fungus causing root rot in trees. Mol. Ecol. 26:6301-6316.

Chung, C.-L., Longfellow, J. M., Walsh, E. K., Kerdieh, Z., Van Esbroeck, G., BalintKurti, P., and Nelson, R. J. 2010. Resistance loci affecting distinct stages of fungal pathogenesis: Use of introgression lines for QTL mapping and characterization in the maize-Setosphaeria turcica pathosystem. BMC Plant Biol. 10:103.

Druzhinina, I. S., Kopchinskiy, A. G., Komon, M., Bissett, J., Szakacs, G., and Kubicek, C. P. 2005. An oligonucleotide barcode for species identification in Trichoderma and Hypocrea. Fungal Genet. Biol. 42:813-828.

El-Mohamedy, R. S. R. 2009. Efficiency of different application methods of biocontrol agents and biocides in control of Fusarium root rot on some citrus rootstocks. Arch. Phytopathol. Plant Prot. 42:819-828.

Forestry Bureau COA. 2013. Diagnosis and Management of Brown Root Rot Disease. Forestry Bureau, Council of Agriculture, Executive Yuan, Taipei City, Taiwan.

Guzmán-Guzmán, P., Porras-Troncoso, M. D., Olmedo-Monfil, V., and Herrera-Estrella, A. 2019. Trichoderma species: Versatile plant symbionts. Phytopathology 109:6-16.

Harman, G. E., Howell, C. R., Viterbo, A., Chet, I., and Lorito, M. 2004. Trichoderma species-opportunistic, avirulent plant symbionts. Nat. Rev. Microbiol. 2:43-56.

Hohmann, P., Jones, E. E., Hill, R. A., and Stewart, A. 2011. Understanding Trichoderma in the root system of Pinus radiata: Associations between rhizosphere colonisation and growth promotion for commercially grown seedlings. Fungal Biol. 115:759-767.

Hood, M. E., and Shew, H. D. 1996. Applications of KOH-aniline blue fluorescence in the study of plant-fungal interactions. Phytopathology 86:704-708.

Huang, H., Sun, L., Bi, K., Zhong, G., and Hu, M. 2016. The effect of phenazine1-carboxylic acid on the morphological, physiological, and molecular characteristics of Phellinus noxius. Molecules 21:613.

Kopchinskiy, A., Komon, M., Kubicek, C. P., and Druzhinina, I. S. 2005. TrichoBLAST: A multilocus database for Trichoderma and Hypocrea identifications. Mycol. Res. 109:658-660.
Mukherjee, P. K., Horwitz, B. A., Herrera-Estrella, A., Schmoll, M., and Kenerley, C. M. 2013. Trichoderma research in the genome era. Annu. Rev. Phytopathol. 51:105-129.

Nicolotti, G., Gonthier, P., and Varese, G. 1999. Effectiveness of some biocontrol and chemical treatments against Heterobasidion annosum on Norway spruce stumps. Eur. J. Forest Pathol. 29:339-346.

Ribera, J., Fink, S., del Carmen Bas, M., and Schwarze, F. W. 2017. Integrated control of wood destroying basidiomycetes combining $\mathrm{Cu}$-based wood preservatives and Trichoderma spp. PLoS One 12:e0174335.

Ribera, J., Tang, A., Schubert, M., Lam, R., Chu, L., Leung, M., Kwan, H., Bas, M., and Schwarze, F. 2016. In-vitro evaluation of antagonistic Trichoderma strains for eradicating Phellinus noxius in colonised wood. J. Trop. For. Sci. 28:457-468.

Richter, D. L., Kangas, L. C., Smith, J. K., and Laks, P. E. 2010. Comparison of effectiveness of wood decay fungi maintained by annual subculture on agar and stored in sterile water for 18 years. Can. J. Microbiol. 56 268-271

Ruano-Rosa, D., Prieto, P., Rincón, A. M., Gómez-Rodríguez, M. V., Valderrama R., Barroso, J. B., and Mercado-Blanco, J. 2016. Fate of Trichoderma harzianum in the olive rhizosphere: Time course of the root colonization process and interaction with the fungal pathogen Verticillium dahliae. BioControl 61:269-282.

Sahashi, N., Akiba, M., Ishihara, M., Miyazaki, K., and Kanzaki, N. 2010. Cross inoculation tests with Phellinus noxius isolates from nine different host plants in the Ryukyu Islands, southwestern Japan. Plant Dis. 94:358-360.

Sahashi, N., Akiba, M., Takemoto, S., Yokoi, T., Ota, Y., and Kanzaki, N. 2014 Phellinus noxius causes brown root rot on four important conifer species in Japan. Eur. J. Plant Pathol. 140:869-873.

Schubert, M., Fink, S., and Schwarze, F. W. 2008. Evaluation of Trichoderma spp as a biocontrol agent against wood decay fungi in urban trees. Biol. Control 45: 111-123.

Schwarze, F. W., Jauss, F., Spencer, C., Hallam, C., and Schubert, M. 2012 Evaluation of an antagonistic Trichoderma strain for reducing the rate of wood decomposition by the white rot fungus Phellinus noxius. Biol. Control 61:160-168.

Tsai, J.-N., Ann, P.-J., and Hsieh, W.-H. 2005. Evaluation of fungicides for suppression of three major wood-decay fungi Phellinus noxius, Rosellinia necatrix and Ganoderma australe in Taiwan. Plant Pathol. Bull. 14: $115-124$

Wu, J., Peng, S. L., Zhao, H. B., Tang, M. H., Li, F. R., and Chen, B. M. 2011. Selection of species resistant to the wood rot fungus Phellinus noxius. Eur. J. Plant Pathol. 130:463-467.

Yedidia, I., Benhamou, N., and Chet, I. 1999. Induction of defense responses in cucumber plants (Cucumis sativus L.) by the biocontrol agent Trichoderma harzianum. Appl. Environ. Microbiol. 65:1061-1070. 